\title{
INCREASING PRECISION OF EXPERIMENTAL DESIGN USING DIFFERENT ANALYSIS MODELS IN GROUNDNUT
}

\author{
${ }^{1}$ Sedeck, F. Sh., M.; ${ }^{1}$ W. Sh. Mahmoud, ${ }^{2 *}$ Zeinab, E. Ghareeb \\ ${ }^{1}$ Oil crop Res., Field Crop Res., Inst., Agric. Res. Cen., Giza, Egypt. \\ ${ }^{2}$ Central Lab. for Design and Stat. Anal. Res., ARC, Giza, Egypt. \\ *Corresponding Author
}

DOI: https://doi.org/10.51193/IJAER.2021.7614

Received: 11 Dec. 2021 / Accepted: 20 Dec. 2021 / Published: 01 Jan. 2022

\begin{abstract}
Really, the traditional designs and classical analysis of variance (ANOVA) may be not adequately to evaluate or screen large number of genotypes and reduce the heterogeneity effect of the new soil. To minimize standard error of differences (SED) between means for catching significance, data were analyzed using various designs and analyses models. This study was purposed to compare traditional randomized complete blocks design (RCBD) and alpha lattice design (ALD) by assessing relative efficiency, using two models of analyses, ANOVA as traditional model and restricted maximum likelihood (REML) as non-traditional one. The field trials were conducted during seasons 2017 to 2019 at Marashda Research Station (new soil), Kena, Egypt. A collection of twenty-five groundnut genotypes were grown in an alpha lattice design with three replications. Results elucidated that the studied genotypes differed significantly for all yield-traits. Relative efficiency of using designs of ALD over RCBD increased experimental accuracy by $72.77-46.23 \%$ and $21.92-14.78 \%$ for pod weight plant $^{-1}$ and pod yield fed $^{-1}$ in both seasons, respectively. Therefore, the results confirmed that the RCBD should be replaced by ALD experiments in testing large number of treatments. Relative precision of using REML analysis over ANOVA increased accuracy by 31.32- $15.88 \%$ and $8.54-1.76 \%$ pod weight plant ${ }^{-1}$ and pod yield fed ${ }^{-1}$ in both seasons, respectively. Generally, REML analysis was more precise and effective in reducing the SED compared to ANOVA for individual and combined analysis. The rank of genotypes mean across the different analyses and seasons were not constant. Then, REML analysis increased the efficiency of genotype selection for further evaluation, providing unbiased estimates. The genotypes that score rank over the studied checks (Giza 6, Ismailia-2, Suhag 104, Suhag 107 and Suhag 110) that are considered the best elite
\end{abstract}


group, included Line-25A and Line-110 genotypes with highest pod yield, followed by Line32A, Line-2B, Line-19A, Intro.-335 and Intro.-504. Therefore, this collection which is the best promising elite group should be effective and satisfactory for successful breeding purposes under Marashda new soil.

Keywords: Alpha lattice design, Coefficient of variation, Precision, Promising elite, RCBD, Relative efficiency, REML model, Selection

\section{INTRODUCTION}

Globally, Peanut (Arachis hypogaea L.) is one of the most important oil seed crops in the world. It is cultivated in an area about 27.34 million hectare with production of 46.75 million tons pods yield (FAO STAT 2019) because of its multiple uses (Panhwar 2005), its high desirable commercially nutritional value, and its ability to grow over a wide range of climatic and soil conditions. In Egypt, it occupies an area of 60 thousand hectare with production of 210 thousand ton pods yield per hectare. Locally adapted genotypes and sustainable farming practices may be the suitable for sustainable agriculture in diverse environments (Abd El-Saber et al. 2020). It is necessary to increase the total production of crops either by increasing their yield potential which can be achieved through breeding promising lines for higher yield or by increasing their cultivated area through growing in the newly reclaimed land. In Egypt, the peanut crop has been received great attention in this field due to its suitability for the nature of sandy reclaimed land (Awadalla and Abbas 2017).

Many experimental designs and data analysis have been used in the agricultural field experiments. Determination the optimal design plays an important role in the accuracy of data collection, advantage data analysis and precise interpretation by reduction the experimental errors. Experimental designs were divided into complete block designs (CBD) as randomized (RCBD) and incomplete block designs (IBD) as alpha lattice ( $\alpha$-lattice). RCBD is one of the most common used designs in breeding and agricultural experiments (Parsad and Gupta 2009); however it is (controlled) restricted to limited treatments number and heterogeneity within blocks (Masood et al. 2008 and Yang et al. 2004). The use of alpha lattice design introduced by (Patterson and Williams, 1976) can solve these restrictions by arranging treatments/plots in some small blocks (contain fewer treatments/plots not total number) under each large block (replication). Then, this experimental layout can maintain the homogeneity among experimental plots, decrease the experimental error, and increase the treatments precision (Masood $\boldsymbol{e} t$ al., 2018, Masood, et al. 2008 and Hinkelman and Kempthorne, 2006, Wu and Dutilleul, 1999). Many researchers have substituted for RCBD with IBD as $\alpha$-lattice (Hinkelman and Kempthorne, 2006). Using multi-environment evaluation is useful in development of adapted superior genotypes to a wide range of environmental conditions. 
A classic statistical technique, Analysis of Variance (ANOVA) that assumes independence of errors, considered as the most common analysis to assess the amount of variation in a dependent variable. In field trial designs, the blocking of experimental field can help to eliminate the systematic effects in environment (units within/block are assumed to be homogeneity). Despite, incomplete blocks usually account for a large amount of heterogeneity in the field, a considerable amount of variation within the block often remains unaccounted for by classical methods of analysis. Modern method, Restricted (or residual) Maximum Likelihood (REML) analysis as that designed to estimate the likelihood or probability of errors can be used to reduce further the unaccounted for variability. Recently, REML method that was generalized by Patterson and Thompson (1976) has been developed for estimating the variance components. Then, using the REML method considers applied treatment factors as fixed effects and the blocking factors as random ones. REML approach is based on maximizing with respect to the variances only the part of the likelihood function that does not depend on fixed effects, contrasting to ANOVA.

REML analysis has many advantages for quantitative traits, is used for the mixed model for balanced and unbalanced data sets and produces the statistics agreed with the results of ANOVA analysis for balanced data however; the problem with this method is that ANOVA estimates may give negative estimates of variance components. The REML method provides adjusted mean estimates for the studied treatments and efficient estimates of treatment effects (Kaya Başar and Firat 2016).

Precision is the ability of an experiment to detect a true treatment effect. The coefficient of variation $(\mathrm{CV})$ is a good index of the precision degree for the treatments compared of each experiment (Leonardo, 2009). The relative efficiency of experimental design over another is measured in terms of reduced error variance, expected mean square error, or average standard error of the difference between treatments means (Masood et al 2008).

The objectives of the present study was to examine the efficiency of alpha lattice design (ALD) over conventional randomized complete block design (RCBD), by different statistical procedures analyses of residual maximum likelihood (REML) method in comparison with the traditional (ANOVA) method, to use the most suitable model in the selection of high-yielding groundnut genotypes in breeding program.

\section{MATERIALS AND METHODS}

\subsection{Experimental procedures}


The experiments were carried out during three successive seasons of 2017 and 2019 at ElMarashda Agricultural Research Station Farm (as a new soil), Kena, Egypt $\left(26.10^{\circ} \mathrm{N}, 32.43^{\circ} \mathrm{E}\right)$ as described in Table (1).

Table 1: Some soil chemical and physical properties of El-Marshda experimental site in 2017 and 2018 seasons and water analysis.

\begin{tabular}{|c|c|c|c|c|c|c|c|c|c|c|c|}
\hline \multicolumn{12}{|c|}{ Soil properties before sowing $(0-30 \mathrm{~cm}$ depth $)$} \\
\hline \multirow{2}{*}{ Season } & \multirow{2}{*}{\multicolumn{2}{|c|}{ Texture grade }} & \multirow{2}{*}{$\mathbf{p H}$} & \multirow{2}{*}{$\begin{array}{c}E C \\
d S ~ m^{-1}\end{array}$} & \multicolumn{4}{|c|}{ Soil Cations meq $\mathrm{L}^{-1}$} & \multicolumn{3}{|c|}{ Soil Anions Meq $\mathrm{L}^{-1}$} \\
\hline & & & & & $\mathbf{C a}^{++}$ & $\mathbf{M g}^{++}$ & $\mathrm{Na}^{+}$ & $\mathbf{K}^{+}$ & $\mathrm{SO}_{4}^{---}$ & $\mathrm{Cl}^{-}$ & $\mathrm{HCO}_{3}$ \\
\hline 2017 & \multirow{2}{*}{\multicolumn{2}{|c|}{ Clay loam }} & 7.85 & 1.49 & 4.80 & 2.20 & 9.20 & 0.40 & 1.80 & 14.90 & 0.54 \\
\hline 2018 & & & 7.90 & 1.72 & 5.10 & 2.10 & 10.50 & 0.50 & 2.19 & 15.10 & 0.49 \\
\hline \multicolumn{12}{|c|}{ Water properties (total soluble salts) } \\
\hline \multirow{2}{*}{\multicolumn{2}{|c|}{ Time operating }} & \multirow{2}{*}{ ppm. } & \multirow{2}{*}{$\mathbf{P H}$} & EC & \multicolumn{4}{|c|}{ Water Cations meq $\mathrm{L}^{-1}$} & \multicolumn{3}{|c|}{ Water Anions Meq $\mathrm{L}^{-1}$} \\
\hline & & & & dS m $\mathbf{m}^{-1}$ & $\mathrm{Ca}^{++}$ & $\mathbf{M g}^{++}$ & $\mathrm{Na}^{+}$ & $\mathbf{K}^{+}$ & $\mathrm{SO}_{4}^{--}$ & $\mathrm{Cl}^{-}$ & $\mathrm{HCO}_{3}$ \\
\hline \multicolumn{2}{|c|}{ Start operating } & 1600 & 7.500 & 2.50 & 7.00 & 6.80 & 10.00 & 0.11 & 2.00 & 20.20 & 1.80 \\
\hline \multicolumn{2}{|c|}{ After1/2 hour } & 1619 & 7.53 & 2.53 & 6.30 & 5.20 & 12.20 & 0.14 & 2.50 & 19.90 & 1.90 \\
\hline
\end{tabular}

These field experiments were conducted to evaluate the yielding ability of twenty-five peanut genotypes and to produce promising plants in newly soil (Marashda, Kena). The 25 studied peanut genotypes included 5 Egyptian commercial cultivars as checks (Giza 6, Ismailia-2, Suhag 104, Suhag 107 and Suhag 110) and 20 selected lines among breeding program. The collection of the tested peanut genotypes kindly provided by Oil Crop Research Department, Field Crop Research Institute (FCRI), Agricultural Research Center (ARC), Egypt. Table (2) presents the genotype name, origin and their pedigree. 
International Journal of Agriculture and Environmental Research

ISSN: 2455-6939

Volume: 07, Issue: 06 "November-December 2021"

Table 2: Name, origin and pedigree for twenty-five groundnut genotypes used in the experiment.

\begin{tabular}{|c|c|c|c|}
\hline Code & Name & Origin & Pedigree \\
\hline G1 & Line-2B & Egypt & Selected as a yield-traits promising genotype \\
\hline G2 & Line-19A & Egypt & Selected as a yield-traits promising genotype \\
\hline G3 & Sohag-104 & Egypt & Line 245 x Geregory \\
\hline G4 & Sohag-110 & Egypt & Line 292 x Geregory \\
\hline G5 & Sohag-107 & Egypt & NC12 x Geregory \\
\hline G6 & Intro.-182 & U.S.A & Florigiant \\
\hline G7 & Intro.-242 & FAO & Shullamit \\
\hline G8 & Intro.-259 & Senegal & $57-422$ \\
\hline G9 & Intro.-267 & Upper Volta & R.M.P12 \\
\hline G10 & Intro.-288 & Senegal & $58-344$ \\
\hline G11 & Intro.-332 & Zambia & Mount Makulu Red \\
\hline G12 & Intro.-335 & Icrisat & Faizpur \\
\hline G13 & Intro.-336 & Icrisat & Exotic 3-5 \\
\hline G14 & Intro.-342 & U.S.A & NC-17 \\
\hline G15 & Intro.-425 & Icrisat & (Rabut33-1xNcAc316)x(53-68xRabut33-1)F7B1 \\
\hline G16 & Intro.-501 & China & Tianhu3 \\
\hline G17 & Intro.-504 & Bolivia & R.C.M444 \\
\hline G18 & Intro.-508 & U.S.A & N.C17 \\
\hline G19 & Intro.-510 & Australia & Vigina Bunch \\
\hline G20 & Intro.-514 & Argentina & Krapovickas \\
\hline G21 & Line-25A & Egypt & Selected as a yield-traits promising genotype \\
\hline G22 & Ismailia-2 & Egypt & Egyptian variety under registration \\
\hline G23 & Giza-6 & Egypt & Egyptian commercial variety \\
\hline G24 & Line-32A & Egypt & Selected as a yield-traits promising genotype \\
\hline G25 & Line-110 & Egypt & Selected as a yield-traits promising genotype \\
\hline
\end{tabular}

\subsection{Experimental design}

The twenty-five genotypes of peanut were sown on the $4^{\text {th }}$ week of April in the field experiments of the first 2 seasons (2017 and 2018) under spray irrigation conditions. The studied peanut genotypes were laid out in alpha lattice design (ALD) with three replications. Each replicate included 25 genotypes, distributed over 5 blocks, with 5 experimental plots per block (Table 3). Plot area was $9.6 \mathrm{~m}^{2}$ consisted of 4 rows, $4 \mathrm{~m}$ long and $60 \mathrm{~cm}$ apart. Hills spacing within rows was $20 \mathrm{~cm}$ with one plant left per hill after thinning and the other cultural practices were carried out as recommendation packages. Looking to elements lack in new soil (Table 1); NPK were added at 45/60/24 kg/feddan. $\mathrm{P}$ was added during soil preparation meanwhile; $\mathrm{N}$ and $\mathrm{K}$ were splitted in 3 equal amounts added at sowing, 30 and 45 days after sowing. Then, foliar spraying 
with macro-elements $(\mathrm{Zn} / \mathrm{Fe} / \mathrm{Mn})$ was done twice at vegetative stage added at 50 and 60 days after sowing to enhance plant growth and production.

In the third summer season (2019), only eleven peanut genotypes of promising selected under new soil were planted in the third field experiment at the same location in randomized complete block design with three replications. All recommended cultural practices for groundnut were applied.

At harvest, 10 guarded plants were randomly taken from each plot to study the following traits: plant height $[\mathrm{PH}(\mathrm{cm})]$, number of branches plant ${ }^{-1}$ [BRA], number of pods plant ${ }^{-1}$ [POD], number of seed plant ${ }^{-1}[\mathrm{SNO}]$, seed weight [SW $\left.(\mathrm{g})\right]$, pod weight plant $^{-1}\left[\mathrm{PWP}^{-1}(\mathrm{~g})\right]$ and shelling percentage\% (SHL). Then, after extraction the outer two rows, the guarded inner rows were combined to determine the pods yield $\mathrm{kg} \mathrm{plot}^{-1}$ and transformed to ton feddan ${ }^{-1}\left[\mathrm{PYF}^{-1}\right]($ feddan $=$ $4200 \mathrm{~m}^{2}$ ).

Table 3: The layout of alpha lattice design with 25 genotypes in 3 complete replications, each replicate is contained 5 blocks (b) and each block contained 5 genotypes (G).

\begin{tabular}{|c|c|c|c|c|c|}
\hline Replicates & $\begin{array}{c}\text { Genotypes/ } \\
\text { Block-1 }\end{array}$ & $\begin{array}{c}\text { Genotypes/ } \\
\text { Block-2 }\end{array}$ & $\begin{array}{c}\text { Genotypes/ } \\
\text { Block-3 }\end{array}$ & $\begin{array}{c}\text { Genotypes/ } \\
\text { Block-4 }\end{array}$ & $\begin{array}{c}\text { Genotypes/ } \\
\text { Block-5 }\end{array}$ \\
\hline \multirow{5}{*}{ Rep-1 } & G -1 & G -6 & $\mathrm{G}-11$ & G - 16 & G -21 \\
\hline & $\mathrm{G}-2$ & G -7 & $\mathrm{G}-12$ & $\mathrm{G}-17$ & $G-22$ \\
\hline & G -3 & G -8 & $\mathrm{G}-13$ & $\mathrm{G}-18$ & $G-23$ \\
\hline & G -4 & G - 9 & $\mathrm{G}-14$ & $\mathrm{G}-19$ & $G-24$ \\
\hline & G -5 & $\mathrm{G}-10$ & $\mathrm{G}-15$ & $G-20$ & $G-25$ \\
\hline \multirow{5}{*}{ Rep-2 } & G -1 & G -2 & G -3 & $\mathrm{G}-4$ & G -5 \\
\hline & G -6 & G -7 & G -8 & G -9 & $\mathrm{G}-10$ \\
\hline & $\mathrm{G}-11$ & $\mathrm{G}-12$ & G -13 & $\mathrm{G}-14$ & $\mathrm{G}-15$ \\
\hline & $G-16$ & $\mathrm{G}-17$ & $\mathrm{G}-18$ & G - 19 & $G-20$ \\
\hline & $G-21$ & $G-22$ & $G-23$ & $\mathrm{G}-24$ & $G-25$ \\
\hline \multirow{5}{*}{ Rep-3 } & $\mathrm{G}-1$ & $G-10$ & $G-14$ & G - 18 & $G-22$ \\
\hline & $\mathrm{G}-2$ & G -6 & G - 15 & $\mathrm{G}-19$ & $\mathrm{G}-23$ \\
\hline & G -3 & G -7 & $\mathrm{G}-11$ & $G-20$ & $G-24$ \\
\hline & G -4 & G -8 & $\mathrm{G}-12$ & $\mathrm{G}-16$ & $G-25$ \\
\hline & G -5 & G -9 & $\mathrm{G}-13$ & $\mathrm{G}-17$ & $\mathrm{G}-21$ \\
\hline
\end{tabular}

\subsection{Statistical procedures}

All data of both seasons were subjected and prepared to the analysis of different statistical procedures. The classic statistical technique (ANOVA) includes complete blocks or incomplete blocks and those that assume independent plot errors (REML). Either ANOVA or REML is an 
appropriate analysis for a general model of alpha lattice design developed by Patterson and Williams (1976): Yield $=\mu+t+r+b+e$

where, $\mu$ denotes the mean value of the observed genotype (t) of the yield received in the incomplete block (b), within replicate (r). However, genotype effects were assumed to be fixed parameters, while replication and block effects within replications were assumed to be random variables. Classical models (complete or incomplete blocks) can be used to analyze normally distributed data, and those that assume independent plot errors; where the random error terms are normal, independent, each with constant variance. This model includes simple random sampling (there are no random effects). Meanwhile, in REML the random error terms are normal, possibly correlated, with possibly unequal variances. The algorithm does not insist on balanced data, unlike ANOVA (Sokal and Rohlf 1995).

\subsubsection{Analysis of Variance (ANOVA)}

All collected data of the two seasons were analyzed using the traditional model of randomized complete blocks (RCBD) technique. Same data were reanalyzed using the analysis of variance (ANOVA) for the alpha lattice design (ALD) developed by Patterson and Williams (1976) for each season.

The relative efficiency (RE\%) of alpha lattice design (ALD) compared with traditional randomized complete block design (RCBD) was calculated as the ratio of the two error mean square $\left(\mathrm{MS}_{\mathrm{e}}\right)$ according Masood et al 2008:

$$
\mathbf{R E} \%=\frac{\text { Mean square of Error in RCBD }}{\text { Mean square of Error in ALD }} * 100
$$

The pod yield/plant data was subjected to the combined analysis of variance across the two seasons for (RCBD) and (ALD) as described by Dean and Voss (1999) after testing the error homogeneity according to Levene's test (1960).

\subsubsection{Restricted maximum likelihood (REML)}

Treatment effects (genotype) were assumed to be fixed parameters, while replication and block within replication effects were supposed to be random variables. The residual maximum likelihood (REML) method was used to estimate parameters (residual variance, deviance, Wald statistic and Akaike coefficient) and use block structures to describe replication effects, incomplete blocks within replication and plot errors (John and Williams, 1995 and Patterson and Williams, 1976). 
Some of produced REML statistics can facilitate the comparison between models as the deviance and Wald statistic. The deviance equals minus twice the REML log-likelihood ignoring a constant depending on the fixed terms. The Wald statistic is computed as the ratio of the squared estimate of the linear trend to its estimated variance, and follows a chi-square distribution in the absence of a trend.

In REML model, results were used to compute the relative efficiency of the method of analysis. Computing efficiency of alpha-lattice design with respect to RCBD (with independent errors) assessed by comparing the average variance of estimates of pair-wise differences by standard error of differences (SED) of genotype effects under RCBD with that of ALD (with dependent errors) according Masood et al (2018):

$$
\begin{gathered}
\mathrm{RE} \%=\frac{\text { Standard error of differences }(\mathrm{SED}) \text { under RCBD })^{2}}{\text { Standard error of differences }(\mathrm{SED}) \text { under } \mathrm{ALD})^{2}} * 100 \\
\text { where, } \mathrm{SED}=\sqrt{\frac{\text { Error Sum of square } * 2}{\text { Replications }}}
\end{gathered}
$$

\subsubsection{Precision of REML analysis $v$ s. the classical ANOVA}

A comparison of models with the same set of fixed effects (treatments/genotypes) was carried out using the standard error of differences, the deviance and Wald statistic. However, the model with the lowest parameter of deviance and standard error of differences is considered as the best one. The highest of Wald statistic value and its significance $(p<0.05)$ is the evidence of the presence of linear trend and importance giving more accurate method than the traditional analysis. All analyses were done using GenStat computer package v.17 (Payne et al., 2015) and to measure the soil heterogeneity and the spatial variability from place to place by using the contour plot graph as a geo-statistical analysis (Lima et al 2017).

\section{RESULTS AND DISCUSSION}

\subsection{Analysis of Variance (ANOVA)}

The analysis of variance (ANOVA) for obtained data of tested traits using RCBD and Alpha Lattice design (ALD) for both 2018 and 2019 seasons is summarized in Tables (4 a and b). Results revealed that the twenty five genotypes had significant variation $(\mathrm{p}<0.05)$ for all measured traits in both seasons, indicating presence of considerable amount of genetic differences between these studied groundnut material. Similar results were reported by (Abd ElSaber et al 2020) that confirmed presence of varietal differences in growth, yield-traits and productivity. 
International Journal of Agriculture and Environmental Research

ISSN: 2455-6939

Volume: 07, Issue: 06 "November-December 2021"

Table 4a: Summary of RCBD and alpha-lattice analysis of variance for all studied traits of groundnut at El-Marashda station during 2017 season.

\begin{tabular}{clccccccccc}
\hline Design & SOV & df & PH & BRA & POD & SNO & SW & SHL & PWP $^{-1}$ & PYF $^{-1}$ \\
\hline \multirow{3}{*}{ RCBD } & Replicates & 2 & 0.85 & 0.96 & 100.84 & 4.38 & 61.97 & 0.62 & $1255.73^{* *}$ & 31256 \\
& Genotypes & 24 & $276.90^{* *}$ & $2.92^{* *}$ & $53.12^{* *}$ & $80.20^{* *}$ & $205.12^{* *}$ & $48.00^{* *}$ & $198.13^{* *}$ & $47033^{* *}$ \\
& Error & 48 & 28.61 & 0.82 & 8.96 & 14.24 & 28.70 & 7.73 & 66.50 & $\mathbf{1 7 1 9 3}$ \\
\hline \multirow{4}{*}{ ALD } & Replicates & 2 & 0.85 & 0.96 & $100.84^{* * *}$ & 4.38 & 61.97 & 0.62 & $1255.73^{* *}$ & 31256 \\
& Blocks/Rep & 12 & $276.79^{* * *}$ & $3.96^{* *}$ & $38.53^{* *}$ & $63.07^{* *}$ & $192.80^{* *}$ & $38.02^{* *}$ & $253.41^{* *}$ & $47921^{* * *}$ \\
& Genotypes & 24 & $145.33^{* *}$ & $1.74^{* *}$ & $35.77^{* *}$ & $53.90^{* *}$ & $123.88^{* *}$ & $31.97^{* *}$ & $146.70^{* *}$ & $36306^{* *}$ \\
& Error & 36 & 33.60 & 0.57 & 10.67 & 15.50 & 28.16 & 8.32 & 38.49 & $\mathbf{1 4 1 0 2}$ \\
\hline Minimum value & & 36.50 & 6.10 & 17.10 & 21.40 & 17.92 & 61.14 & 26.20 & 592.67 \\
Maximum value & & 69.17 & 9.70 & 32.50 & 40.59 & 54.06 & 76.80 & 55.31 & 1164.60 \\
\hline
\end{tabular}

Abbreviations of RCBD: Randomized Complete Block Design and ALD: Alpha Lattice.

PH: plant height $(\mathrm{cm})$, BRA: number of branches/plant, POD: number of pods/plant, SNO: number of seed/plant, SW: seed weight/plant (g), PWP: pod weight $\left(\mathrm{g} \mathrm{plant}^{-1}\right)$, PYF: pods yield $\left(\mathrm{kg} \mathrm{fed}^{-1}\right)$ and SHL:

shelling percentage $(\%)$.

Regarding replications in RCBD, it is noted that all traits were not significant except pod yield fed $^{-1}$ in the $2^{\text {nd }}$ season and pod weight plant ${ }^{-1}$ in both seasons. Therefore, it is may be due to the replication failed in accounting the intra-site heterogeneity (Kirk, 1995) for having great size extent and heterogeneity within replication.

Table 4b: Summary of RCBD and alpha-lattice analysis of variance for all studied traits of groundnut at El-Marashda station during 2018 season.

\begin{tabular}{clccccccccc}
\hline Design & SOV & df & PH & BRA & POD & SNO & SW & SHL & PWP-1 $^{\text {PYF }}$ \\
\hline \multirow{2}{*}{ RCBD } & Replicates & 2 & 41.52 & 0.04 & 20.36 & 4.90 & 2.88 & 27.10 & $225.44^{* * *}$ & $143113^{*}$ \\
& Genotypes & 24 & $108.35^{* *}$ & $2.90^{* *}$ & $86.87^{* *}$ & $162.23^{* *}$ & $456.17^{* *}$ & $57.91^{* *}$ & $451.47^{* *}$ & $61574^{*}$ \\
& Error & 48 & 8.49 & 0.75 & 18.75 & 11.00 & 16.66 & 9.68 & 30.81 & 28595 \\
\hline \multirow{2}{*}{ ALD } & Replicates & 2 & $41.52^{* *}$ & 0.04 & 20.36 & 4.90 & 2.88 & 27.10 & $225.44^{* *}$ & $143113^{* *}$ \\
& Blocks/Rep & 12 & $108.34^{* *}$ & $4.65^{* *}$ & $81.99^{* *}$ & $129.44^{* *}$ & $464.61^{* *}$ & $36.62^{* *}$ & $586.96^{* *}$ & 42962 \\
& Genotypes & 24 & $61.77^{* *}$ & $1.30^{* *}$ & $60.68^{* *}$ & $103.30^{* *}$ & $233.22^{* *}$ & $42.32^{* *}$ & $188.01^{* *}$ & $59913^{* *}$ \\
& Error & 36 & 6.26 & 0.51 & 15.13 & 10.81 & 15.98 & 11.10 & 21.07 & 24913 \\
\hline Minimum value & & 47.58 & 7.33 & 18.57 & 20.37 & 16.97 & 62.12 & 24.00 & 652.13 \\
Maximum value & & 72.89 & 10.33 & 40.28 & 45.79 & 60.13 & 78.76 & 60.31 & 1272.32 \\
\hline
\end{tabular}

Abbreviations of RCBD: Randomized Complete Block Design and ALD: Alpha Lattice.

PH: plant height $(\mathrm{cm})$, BRA: number of branches/plant, POD: number of pods/plant, SNO: number of seed/plant, SW: seed weight/plant (g), PWP: pod weight $\left(\mathrm{g} \mathrm{plant}^{-1}\right)$, PYF: pods yield $\left(\mathrm{kg} \mathrm{fed}^{-1}\right)$ and SHL: shelling percentage $(\%)$.

However, blocks within replication (blocks/rep) in alpha lattice design (ALD) recorded highly significant effects for all traits in both seasons except for pod yield ton fed ${ }^{-1}$ only in the $2^{\text {nd }}$ season. These obtained results suggested that ALD containing 5 blocks under each replication may be effective in detecting and removing the significant differences within the relatively large 
replication. Then, using ALD analysis could be fitted in testing relatively large number of treatments. Many authors confirmed same results as Raza and Masood (2009) and Abd-ElShafi (2014).

\subsubsection{Relative Efficiency of ALD vs. RCBD under ANOVA analysis}

In fact, the important advantage of alpha-lattice design (ALD) is possibility to be analyzed as RCBD (Cochran and Cox, 1957). Therefore, the comparison between ALD vs. RCBD for the same data set analysis was conducted using some statics and relative efficiency. These statics were experimental error, coefficient of variation (CV \%) and standard error of differences (SED) as shown in Tables (5a and b). Then, relative efficiency (RE \%) was assessed by comparing the error mean square of ALD with that of RCBD.

Data presented in Tables (5a and b) revealed the values of coefficient of variation (CV \%) for studied yield traits in groundnut. Estimates of CV \% in RCBD ranged between 4.10- $4.40 \%$ and 4.40- $4.66 \%$ in ALD for shelling percentage trait in both seasons, respectively, recording the lowest $\mathrm{CV} \%$ that was due to the calculated trait.

However, RCBD scored high CV \% recording $25.90 \%$ and $21.00 \%$ for pod weight plant ${ }^{-1}$ and pod yield $\mathrm{fed}^{-1}$ in the $1^{\text {st }}$ and $2^{\text {nd }}$ seasons, respectively. Meanwhile, CV \% values in ALD were $19.73 \%$ for seed weight plant ${ }^{-1}$ and $19.56 \%$ for pods yield fed $^{-1}$ in the $1^{\text {st }}$ and $2^{\text {nd }}$ seasons, respectively. The observed SED value was positively correlated with CV \% values, clarifying the effects of the degree of precision of compared treatments and is consider a good index of the experiment reliability.

It is clear that error mean squares and SED recorded the lowest estimates with acceptable CV \% for alpha-lattice (ALD) experiment in comparison to RCBD for most evaluated traits in the $1^{\text {st }}$ season and all traits except shelling percentage in the $2^{\text {nd }}$ season.

In general, alpha lattice analysis decreased the experimental error in most cases, followed by acceptable decreasing CV \% and S.E.-diff. estimates. These results are in accordance with Abdelkawy et al 2020, Duppala et al. (2018), Masood et al. (2018) and Ghareeb et al. (2015). 
International Journal of Agriculture and Environmental Research

ISSN: 2455-6939

Volume: 07, Issue: 06 "November-December 2021"

Table 5a: Estimated residual mean squares, coefficient of variation (CV \%), standard error of differences (SED) and relative efficiency (RE \%) of alpha lattice design $v s$. RCBD during 2017 season.

\begin{tabular}{|c|c|c|c|c|c|c|c|}
\hline \multirow{2}{*}{$\overbrace{\text { Trait }}$ Design } & \multicolumn{3}{|c|}{ RCBD } & \multicolumn{3}{|c|}{ Alpha-lattice } & \multirow{2}{*}{$\begin{array}{c}\text { Efficiency } \\
\text { (RE \%) }\end{array}$} \\
\hline & Error & CV\% & S.E.-diff. & Error & CV\% & S.E.-diff. & \\
\hline Plant height & 28.61 & 10.60 & 4.37 & 33.60 & 11.50 & 4.73 & 85.13 \\
\hline Branches no. plant ${ }^{-1}$ & 0.82 & 11.50 & 0.74 & 0.57 & 9.90 & 0.61 & 145.66 \\
\hline Pods no. plant ${ }^{-1}$ & 8.96 & 11.60 & 2.44 & 10.67 & 15.00 & 2.67 & 83.91 \\
\hline Seed no. plant $^{-1}$ & 14.24 & 13.20 & 3.08 & 15.50 & 11.50 & 3.22 & 91.84 \\
\hline Seed weight plant ${ }^{-1}$ & 28.70 & 16.90 & 4.37 & 28.16 & 16.10 & 4.33 & 101.90 \\
\hline Shelling \% & 7.73 & 4.10 & 2.27 & 8.32 & 4.40 & 2.36 & 92.91 \\
\hline Pod weight plant ${ }^{-1}$ & 66.50 & 25.90 & 6.66 & 38.49 & 19.73 & 6.02 & 172.77 \\
\hline Pods yield fed ${ }^{-1}$ & 17193 & 16.70 & 107.10 & 14102 & 15.13 & 96.96 & 121.92 \\
\hline
\end{tabular}

RE \% of ALD $v s$. RCBD = Error under RCBD/ Error under alpha lattice*100.

With regard to the relative efficiency (RE \%), estimates presented in Tables (5a and b) point to the comparison of traditional RCBD residual mean square (error) with ALD residual. Estimated relative efficiency greater than $100 \%$ indicated the suitability of alpha-lattice (ALD). Results revealed that alpha-lattice increased experimental precision by 45.66, 1.90, 72.77 and $21.92 \%$ over RCBD for number of branches plant ${ }^{-1}$, seed weight plant ${ }^{-1}$, pod weight plant ${ }^{-1}$ and pod yield fed $^{-1}$, respectively, in the $1^{\text {st }}$ season. However, ALD in the $2^{\text {nd }}$ season raised the precision for all traits except shelling percentage ranging between 1.80 to $46.93 \%$. Greater values than 100 proposed that alpha-lattice (ALD) is more appropriate and efficient design than RCBD, minimizing experimental error, CV\% and SED (Abdelkawy et al. 2020, Duppala et al. 2018, Masood et al. 2018 and Ghareeb et al. 2015).

Table 5b: Estimated residual mean square, coefficient of variation (CV \%), standard error of differences (SED) and relative efficiency (RE \%) of alpha lattice design vs. RCBD during 2019 season.

\begin{tabular}{|c|c|c|c|c|c|c|c|}
\hline \multirow{2}{*}{$\mathrm{P}_{\text {Trait }}$ Design } & \multicolumn{3}{|c|}{ RCBD } & \multicolumn{3}{|c|}{ Alpha-lattice } & \multirow{2}{*}{$\begin{array}{c}\text { Efficiency } \\
\text { (RE \%) }\end{array}$} \\
\hline & Error & CV\% & S.E.-diff. & Error & CV\% & S.E.-diff. & \\
\hline Plant height & 8.49 & 5.10 & 2.38 & 6.26 & 4.35 & 2.04 & 135.60 \\
\hline Branches no. plant ${ }^{-1}$ & 0.75 & 9.90 & 0.71 & 0.51 & 8.13 & 0.58 & 146.93 \\
\hline Pods no. plant ${ }^{-1}$ & 18.75 & 15.00 & 3.54 & 15.13 & 13.52 & 3.18 & 123.88 \\
\hline Seed no. plant $^{-1}$ & 11.00 & 11.50 & 2.71 & 10.81 & 11.37 & 2.69 & 101.80 \\
\hline Seed weight plant ${ }^{-1}$ & 16.66 & 16.10 & 3.33 & 15.98 & 15.82 & 3.26 & 104.27 \\
\hline Shelling \% & 9.68 & 4.40 & 2.54 & 11.10 & 4.66 & 2.72 & 87.20 \\
\hline Pod weight plant ${ }^{-1}$ & 30.81 & 16.40 & 4.53 & 21.07 & 13.59 & 3.75 & 146.23 \\
\hline Pods yield fed $^{-1}$ & 28595 & 21.00 & 138.10 & 24913 & 19.56 & 128.90 & 114.78 \\
\hline
\end{tabular}

RE \% of ALD $v s$. RCBD = Error under RCBD/ Error under alpha lattice*100. 
International Journal of Agriculture and Environmental Research

ISSN: 2455-6939

Volume: 07, Issue: 06 "November-December 2021"

\subsection{Restricted maximum likelihood (REML)}

From previous results, relative efficiency of ALD vs. RCBD under ANOVA analysis purposed that using alpha-lattice design in testing large number of genotypes (treatments) can provide more accurate estimate than the randomized complete block for most traits (Patterson and Hunter, 1983 and Yau, 1997), especially in groundnut pod yield.

An alternative analysis of designs for an experiment with a large number of treatments is REML model. The comparison between ALD vs. RCBD analysis for the same data set was conducted using the relative efficiency and some parameters i.e. variance residual, Wald statistic, Deviance and standard error of differences (SED) estimates as shown in Table (6). Masood et al. (2018), Shalaby et al. (2018) and Singh et al (2013 and 2003) compared between lattice designs with RCBD using REML analysis in different crops.

Statistically, it's known that the choosing the model (ALD or RCBD) using REML analysis based on the lowest values of residual, Deviance and SED estimates with higher Wald statistic and RE \% value (Shalaby et al. 2018, Piepho and Möhring 2011, Sokal and Rohlf 1995 and Meyer 1985).

Data exist in Table (6) cleared that the genotypes had highly significant effect for all pod yield traits except pod yield $\left(\mathrm{kg} \mathrm{fed}^{-1}\right)$ in the $2^{\text {nd }}$ season for both ALD and RCBD. The variance residual (error) was decreased from 66.50, 17193, 30.81 and 28595 in RCBD to 39.84, 13860, 21.88 and 26092 in ALD for pod weight plant ${ }^{-1}$ and pod yield fed $^{-1}$ traits in each season, respectively.

Simultaneously, SED estimates were reduced from 6.66, 107.10, 4.53 and 138.10 in RCBD to 5.81, 102.80, 4.21 and 136.90 in ALD for pod weight plant ${ }^{-1}$ and pod yield fed ${ }^{-1}$ traits in each season, respectively. Masood et al (2008), Singh et al (2003) and Yau (1997) used SED in experimental evaluation.

Data of estimated deviance parameter was lower in ALD (274.68, 546.15, 241.17 and 572.83) inverse RCBD that had (282.27, 548.91, 245.35 and 573.33) for pod weight plant ${ }^{-1}$ and pod yield fed $^{-1}$ traits across both seasons, respectively. Shalaby et al. (2018) and Singh et al (2013) used estimated deviance in evaluating statistical models in cotton and barley grain yield.

Meanwhile, ALD data recorded significant and higher Wald statistic value (87.82, 68.94, 277.06 and 53.92) compared to $\operatorname{RCBD}(71.51,65.65,351.64$ and 51.68) for studied pod yield traits. These results indicated the presence of linear trend and the importance using ALD model than the traditional RCBD (Singh et al 2003). 
REML measures showed that the lower acceptable values of error, SED and Deviance with higher Wald statistic value of ALD compared to RCBD for all pod yield traits in both seasons. Then, ALD could be adequately fitted to the analysis compared to RCBD. Also, reducing standard error of differences (SED) helped to determine the significant smaller differences among genotypes means.

\subsubsection{Efficiency of ALD vs. RCBD for pod yield under REML analysis}

Using the previous SED results, the relative efficiency (RE \%), estimates were computed as showing in Table (6). The RE \% estimates were in ALD greater than $100 \%$ registering increase by (31.32 and $15.88 \%)$ for pod weight plant ${ }^{-1}$ and $(8.54$ and $1.76 \%)$ for pod yield fed ${ }^{-1}$ in both seasons, respectively.

The above-mentioned results of REML model cleared that alpha lattice design (ALD) was more efficient than RCBD for all the studied pod yield traits in both seasons. These results are similar to those of Shalaby et al. (2018) and Singh et al (2013 and 2003).

Generally, measures of either ANOVA or REML analysis for alpha-lattice design ensured the desired precision parameters (lower acceptable values of residual, SED and Deviance with higher Wald statistic value) in both seasons. Therefore, using ALD (alpha-lattice designs) was a corrective analysis to provide more accurate estimate than the RCBD (randomized complete block design) based on ANOVA or REML analysis.

\subsubsection{Precision of REML model vs. ANOVA method in ALD analysis}

Although classical ALD (alpha-lattice designs) model often account for a large amount of variability (replication and blocks within replication) in the field, but traditional variance analysis that depends on least squares analysis (ANOVA) method assuming independent errors effects provides biased estimates (Galwey 2006). The REML assumed replication and blocks within replications effects to be random variables. Then using REML analysis was to describe changing variances across these factors levels replications or blocks calculating unbiased estimates (Jonson and Thompson 1995).

Results in Table (6) revealed the comparison between the used models; traditional ANOVA of ALD and alternative REML using SED. Desired lower SED values were obtained by using REML model. In ALD analysis, SED values reduced to 5.81, 102.80, 4.21 and 136.90 for pod weight plant $^{-1}$ and pod yield fed $^{-1}$ in each season, respectively; after using REML analysis compared to $6.02,115.20,4.4$ and 153.20 for pod weight plant ${ }^{-1}$ and pod yield fed $^{-1}$ in each season, respectively; with ANOVA. 
International Journal of Agriculture and Environmental Research

ISSN: 2455-6939

Volume: 07, Issue: 06 "November-December 2021"

Table 6: Some estimated REML parameters Wald statistic, Deviance, SED and relative efficiency (RE \%) of ALD vs. RCBD during both seasons of 2017 and 2018, and precision of REML vS. ANOVA.

\begin{tabular}{|c|c|c|c|c|c|c|c|c|c|}
\hline \multirow{3}{*}{ Parameter } & \multirow{3}{*}{ Design } & \multicolumn{4}{|c|}{2018} & \multicolumn{4}{|c|}{2019} \\
\hline & & \multicolumn{2}{|c|}{ Pod weight plant $^{-1}$} & \multicolumn{2}{|c|}{ Pod yield Kg fed ${ }^{-1}$} & \multicolumn{2}{|c|}{ Pod weight plant $^{-1}$} & \multicolumn{2}{|c|}{ Pod yield Kg fed $^{-1}$} \\
\hline & & RCBD & ALD & RCBD & ALD & RCBD & ALD & RCBD & ALD \\
\hline \multirow{2}{*}{ Residual } & ANOVA & \multirow{2}{*}{66.50} & 38.49 & \multirow{2}{*}{17193} & 14102 & \multirow{2}{*}{30.81} & 21.07 & \multirow{2}{*}{28595} & 24913 \\
\hline & REML & & 39.84 & & 13860 & & 21.88 & & 26092 \\
\hline \multirow{2}{*}{ Wald statistic } & ANOVA & \# & \# & \# & \# & \# & \# & \# & \# \\
\hline & REML & $71.51^{* *}$ & $87.82^{* *}$ & $65.65^{* *}$ & $68.94^{* *}$ & $351.64^{* *}$ & $277.06^{* *}$ & $51.68^{*}$ & $53.92^{*}$ \\
\hline \multirow[b]{2}{*}{ Sign. (5\%) } & ANOVA & $<0.001$ & $<0.001$ & $<0.001$ & $<0.005$ & $<0.001$ & $<0.001$ & $<0.012$ & $<0.014$ \\
\hline & REML & $<0.001$ & $<0.001$ & $<0.001$ & $<0.002$ & $<0.001$ & $<0.001$ & $<0.012$ & $<0.014$ \\
\hline \multirow{2}{*}{ Deviance } & ANOVA & \# & \# & \# & \# & $\#$ & \# & \# & \# \\
\hline & REML & 282.27 & 274.68 & 548.91 & 546.15 & 245.35 & 241.17 & 573.33 & 572.83 \\
\hline \multirow{2}{*}{ S.E-diff. } & ANOVA & 6.66 & 6.02 & 107.10 & 115.20 & 4.53 & 4.45 & 138.10 & 153.20 \\
\hline & REML & 6.66 & 5.81 & 107.10 & 102.80 & 4.53 & 4.21 & 138.10 & 136.90 \\
\hline \multirow{2}{*}{ RE\% } & ANOVA $^{\dagger}$ & \multirow{2}{*}{\multicolumn{2}{|c|}{$\frac{172.771}{131.32}$}} & \multirow{2}{*}{\multicolumn{2}{|c|}{$\begin{array}{l}121.92 \\
108.54\end{array}$}} & \multirow{2}{*}{\multicolumn{2}{|c|}{$\begin{array}{l}146.23 \\
115.88\end{array}$}} & \multirow{2}{*}{\multicolumn{2}{|c|}{$\begin{array}{l}114.78 \\
101.76\end{array}$}} \\
\hline & $\mathrm{REML}^{\dagger \dagger}$ & & & & & & & & \\
\hline \multicolumn{2}{|c|}{$\begin{array}{l}\text { Precision REML } v s \text {. } \\
\text { ANOVA (in ALD) }{ }^{++}\end{array}$} & & 103.61 & & 112.06 & & 105.70 & & 111.91 \\
\hline
\end{tabular}

RCBD: randomized complete block design, ALD: alpha lattice design, ANOVA: Analysis of Variance, REML: Restricted (or residual) Maximum Likelihood, SED.: Standard error of differences, Sign. (5\%): Wald test significant.

Deviance $=-2 \log$ likelihood (sub-model) deviance omits constants which depend on fixed model fitted.

\#: means no estimate (fixed model fitted)

$\uparrow \mathbf{R E} \%$ of ALD vs. RCBD under ANOVA = MS of error under RCBD/ MS of error under alpha*100.

$\dagger+\mathbf{R E} \%$ of ALD vs. RCBD under REML $=(\mathrm{SED} \text { under RCBD })^{2} /(\text { SED under alpha })^{2 * 100}$.

++ Precision REML vs. ANOVA: The results were extended to detect the most précised REML models using (SED)

estimated under ALD.

The alternative REML was more effective in comparison with the traditional ANOVA, scoring increase in REML precision with values of 103.61-105.70 and 112.06-111.91 for pod weight plant $^{-1}$ and pod yield $\mathrm{fed}^{-1}$ in each season, respectively.

REML model increase the precision compared with traditional analysis of RCBD and lattice as well as it was very close to detect significant difference between genotype means in the pod yield traits. These results were similar those obtained by Mick, 2010).

\subsection{Combined analysis for pod yield traits across seasons}

The efficient multi-environment testing program to provide information subject to available genotypes has been studied by many workers. Evaluation under multi-environment for different crops was considered for minimizing the variance of differences between genotypes.

The results of Levene (1960) test confirmed the homogeneity of variances for only pod yield $\mathrm{Kg}$ fed $^{-1}$ trait which allowed the combined analysis over two seasons of 2017 and 2018 under both 
designs (RCBD and ALD). Results in (Table 7) showed significant differences among genotypes for pod yield fed ${ }^{-1}$ under both designs (RCBD and ALD) and REML analysis, pointing to the considerable genotypic effect. The season and genotypes $\times$ seasons interaction effect was not significant in both RCBD and ALD designs indicated that genotypes gave same responses under different seasons. The blocks effect under replication in ALD was highly significant among seasons, indicating that blocks were effective in remove the heterogeneity within or between blocks.

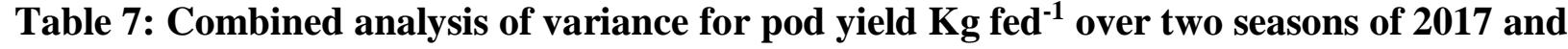
2018 under both designs (RCBD and ALD) with SED of REML at El-Marashda station.

\begin{tabular}{|c|c|c|c|c|c|c|}
\hline \multirow[b]{2}{*}{ S.O.V. } & \multirow[b]{2}{*}{ df } & \multicolumn{2}{|c|}{ RCBD } & \multicolumn{2}{|c|}{ ALD } & \multirow{2}{*}{$\begin{array}{c}\text { REML } \\
\text { component }\end{array}$} \\
\hline & & $\begin{array}{c}\text { Mean } \\
\text { Square }\end{array}$ & $\begin{array}{c}\text { Explained } \\
\text { SS (\%) } \\
\end{array}$ & $\begin{array}{c}\text { Mean } \\
\text { Square }\end{array}$ & $\begin{array}{c}\text { Explained } \\
\text { SS }(\%) \\
\end{array}$ & \\
\hline Seasons & 1 & 18194 & 0.35 & 18194 & 0.35 & \\
\hline Seasons. Replicate & 4 & 87191 & 6.74 & $87191^{* *}$ & 6.74 & 1958 \\
\hline Season. Replicate. Block & 24 & ---- & --- & $41848^{* *}$ & 18.22 & 3679 \\
\hline Genotypes & 24 & $99496^{* *}$ & 46.18 & $84258^{* *}$ & 39.10 & \\
\hline Seasons. Genotypes & 24 & 9099 & 4.22 & 11955 & 5.55 & \\
\hline Residual & 72 & 22895 & 42.50 & 19507 & 27.16 & 19848 \\
\hline Total & 149 & & 100.00 & 34706 & 100.00 & \\
\hline \multicolumn{2}{|l|}{ S.E. (Diff.) } & \multicolumn{2}{|c|}{87.40} & \multicolumn{2}{|c|}{95.84} & 85.70 \\
\hline
\end{tabular}

*** $*$ significant at $\mathrm{p}<0.01$ and $\mathrm{p}<0.05$ level respectively, $\mathrm{SS}=$ sum of squares.

S.E. (Diff.): Average Standard errors of differences of significant genotypes means.

The partitioning of sum of squares indicated that blocks/ replication/ season contribute at $18.22 \%$ for pod yield $\mathrm{Kg} \mathrm{fed}^{-1}$ (Table 7), indicating the importance of blocking effect. Meanwhile, resulted ALD analysis detected that values of Residual or experimental error (19507) with contribution of $(27.16 \%)$ was lower than RCBD (22895) with contribution of (42.50\%) from total variance of pod yield $\mathrm{Kg} \mathrm{fed}^{-1}$. Then, ALD analysis reduced the Residual \% enhancing the efficiency of the experiment to detect differences for genotype selection in groundnut improvement programs. Nkhoma et al. (2020) gave similar results by conducting the combined analysis for alpha lattice design in cowpea yield.

Based on the previous comparison among the studied statistical models, the results in Table (7) showed that REML analysis recorded the lowest value of SED of significant genotypes means. Therefore, using REML provides a more accurate method than the traditional analysis (RCBD and ALD) in testing large number of genotypes and improves accuracy of comparison between every pair of genotypes. In general, REML method could provide estimated means that are 
unbiased or at least less biased, best linear unbiased estimate (BLUE) than those obtained by traditional analysis for designs of RCBD and ALD (Galwey 2006).

The computed error mean square (residual variance) was mainly used to assess the variability of the different analysis models for the same data set. Then, residual has an important effect on the geo-statistical analysis and measurement soil heterogeneity (Lima et al 2017). The residual for pod yield fed $^{-1}$ resulting from different analysis models was used to evaluate effects of some analyses evaluate effects of soil heterogeneity and the spatial variability from place to place.

The use of REML combined analysis was more efficient than combined ANOVA analysis under classical models (RCBD and ALD) because of better controlling of site variability due to effective accounting for heterogeneity of effects among pair of treatments (SED) and proved unbiased mean values. Then, these models provided residual (average/ 2 seasons) that was used in mapping of spatial heterogeneity and variability in soil properties (Gabriel Soropa et al. 2021).

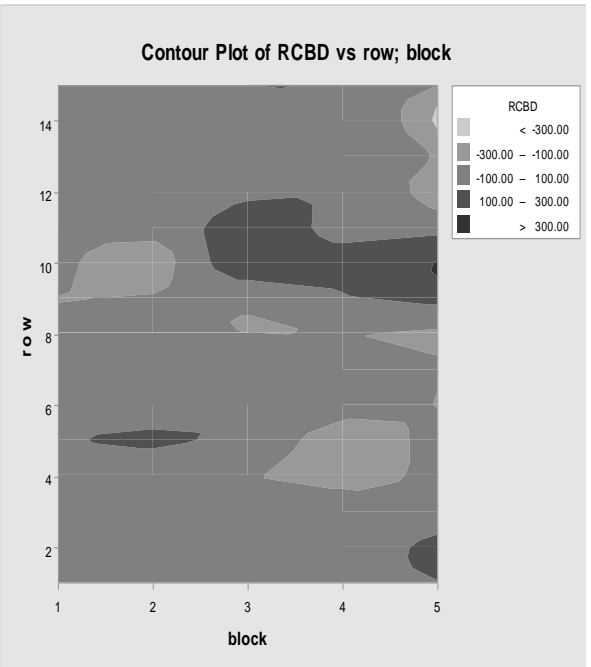

Counter plot of RCBD

(ANOVA) residual Row vs. block

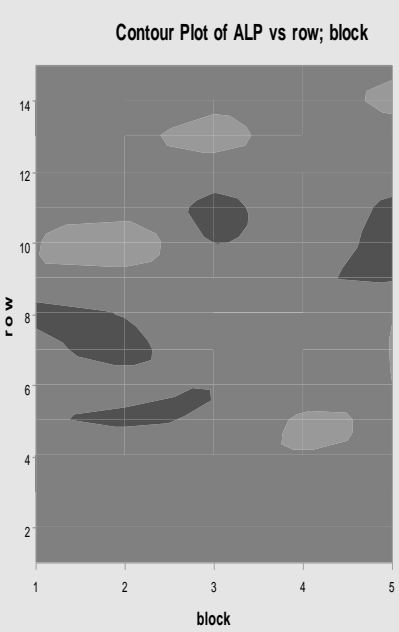

Counter plot of ALD

(ANOVA) residual Row vs. block

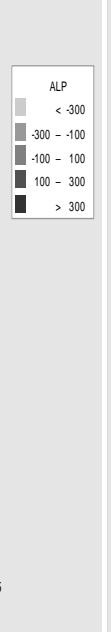

Counter plot of ALD (REML) residual Row vs. block

Figure 4: Differences between RCBD, ALD and REML analysis models in mapping of soil heterogeneity by contour plot graph with correcting plot-plot differences.

The residuals of models analyses were used to get the contour plot graph for each model analysis. This contour plot graph in Figure (4) illustrated the geo-statistical map, showing that REML analysis role in correcting the effect of present extremely values among place to place data. Therefore, REML analysis considered as the best studied analysis models for pod yield fed 
${ }^{1}$ to capture all the spatial variability (plot-plot differences) and gave the true values of the studied genotypes by best linear unbiased estimate (BLUE).

\subsection{Comparison of RCBD, ALD and REML analyses for pod yield means}

Many researchers confirmed that using different models of analysis (as RCBD and alpha lattice design) generated differences between the ranks of genotypes through seasons. Estimated genotypes mean ranking of pod yield $\mathrm{kg} \mathrm{fed}^{-1}$ using the three (RCBD, ALD and REML) analysis models for both 2017 and 2018 seasons were presented in Table (8).

These differences in rank may be due to the effect of environmental factors and their interactions with genotypes. The combined genotype means and their ranks were estimated to avoid the differences between the ranks of genotypes through seasons. Then, the differences between the ranks of genotypes here attributed to the effect of model analysis only.

The comparisons of the genotypes rank based on combined means under either unadjusted (RCBD) or adjusted (ALD) and predicted (REML model) were also included (Table 8). Results exhibited that promising Line-25A and Line-110 genotypes had the highest pod yield in all cases during the two seasons, recording (1218.50 and $\left.1041.00 \mathrm{~kg} \mathrm{fed}^{-1}\right),\left(1338.65\right.$ and $1126.90 \mathrm{~kg}^{-} \mathrm{fed}^{-}$ ${ }^{1}$ ) and (1246.82 and $1054.00 \mathrm{~kg} \mathrm{fed}^{-1}$ ) as combined under unadjusted (RCBD) or adjusted ALD and REML models, respectively. The highest yielding genotypes ranks over the studied checks (Giza 6, Ismailia-2, Suhag 104, Suhag 107 and Suhag 110) considered the best elite ones. Based on the three models, Line-25A and Line-110 genotypes scored the highest pod yield, followed by Line-32A, Line-2B, Line-19A, Intro.-335 and Intro.-504, collecting the best promising elite group.

According to these results, the selected eleven genotypes considered elite group and should be taken into consideration by groundnut breeders in planning breeding program for groundnut yield. These results are in accordance with those obtained by Rangaswamy (2010) and Abd ElSaber et al (2020). 
International Journal of Agriculture and Environmental Research

ISSN: 2455-6939

Volume: 07, Issue: 06 "November-December 2021"

Table 8: Changes in rank of 25 groundnut genotype means resulted from combined analysis using different models (RCBD, ALD and REML) analysis for pod yield fed ${ }^{-1}$.

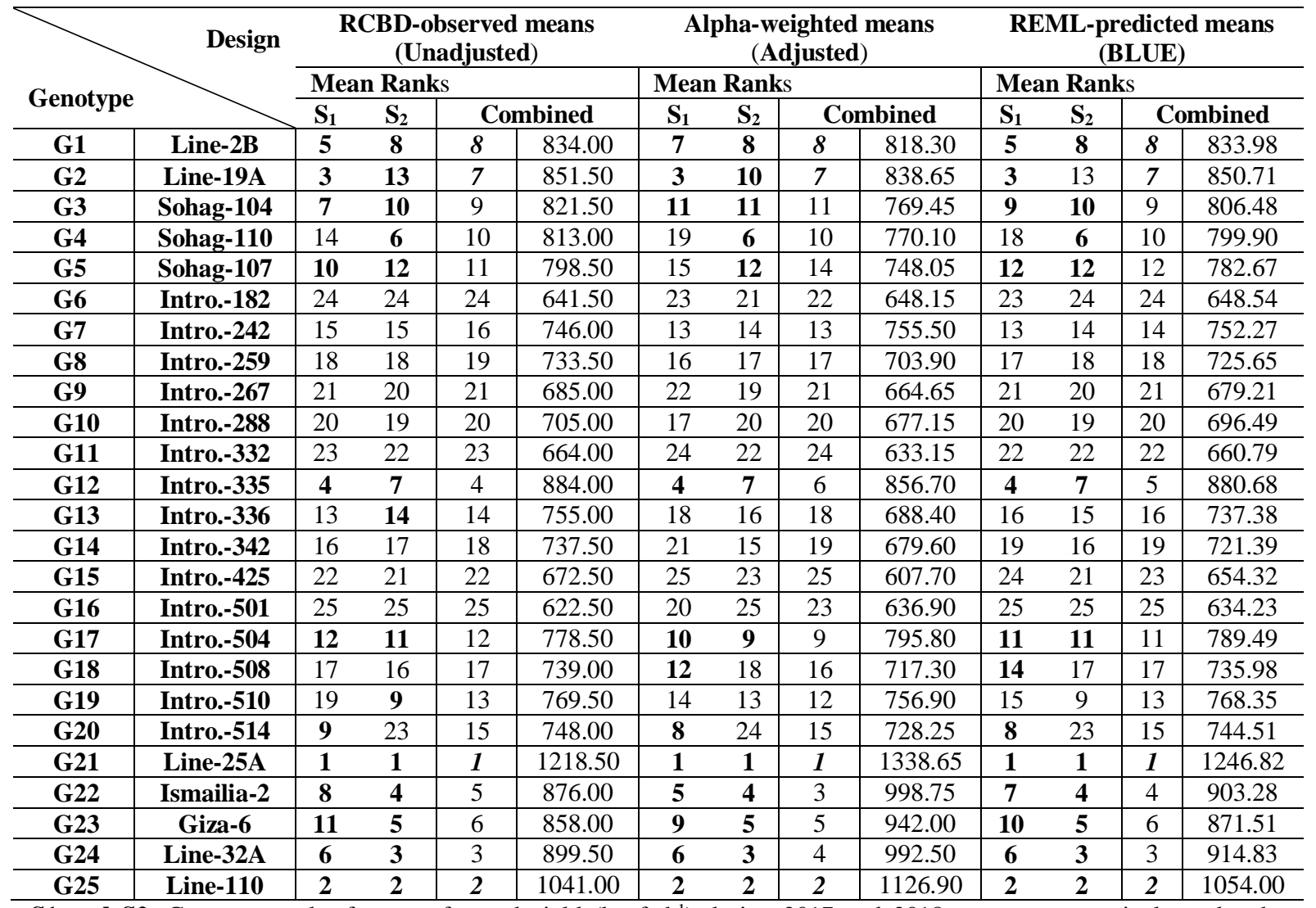

S1 and S2: Genotype rank of means for pod yield $\left(\mathrm{kg} \mathrm{fed}^{-1}\right)$ during 2017 and 2018 seasons, respectively under the different models. BLUE: best linear unbiased estimate.

\subsection{New land-adapted genotypes advantages}

Based on the last selection, the best eleven genotypes elite were evaluated in 2019 season for the studied traits under new soil. Results in Figure (5) showed the differences between means of $1^{\text {st }}$ two years (2017-2018) and the $3^{\text {rd }}$ one (2019) for groundnut pod yield and its shelling ratio $\%$. All the tested genotypes significantly surpassed the highest yielder genotypes and shelling ratio $\%$ combined across the two seasons. These genotypes response were used to calculate increase ratio in the two previous traits based on more soil-adapted. Results showed that the selected genotypes produced high values of pods yield fed ${ }^{-1}$ and shelling traits. The heaviest pod yielder ranged between 1269.65 to $802.70 \mathrm{~kg} \mathrm{fed}^{-1}$ for Line-25A and Sohag-107, respectively, pointing to increase in pod yield weight for all genotypes except for Line-19A and Sohag-110. While, the highest shelling increase percent ranged between $113.27 \%$ to $96.11 \%$ for Intro.-335 and Line$25 \mathrm{~A}$, respectively, referring to increase in shelling\% for all genotypes except for Line-25A 
(96.11\%) only. Regarding the weights of pods yield trait, Ismailia-2, Sohag-104 and Line-2B genotype recorded the heaviest increase in weights with increase percent about $(34.28,19.16$ and $12.62 \%)$ in the $3^{\text {rd }}$ season. However, the highest shelling percentages $(113.27,109.82$ and $109.04 \%)$ were recorded by Intro.-335, Line-19A and Sohag-110 with increase percent about (13.27, 9.82 and 9.04\%)._These results are in harmony with those reported by (Rangaswamy 2010).
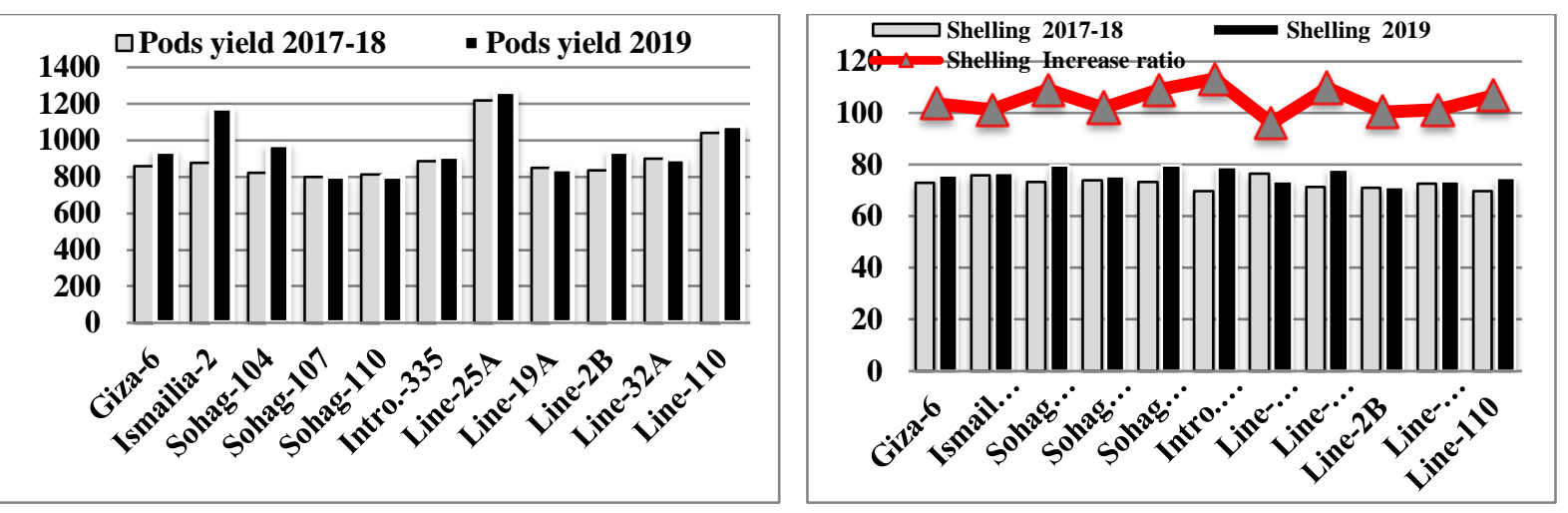

Figure 5: Differences between combined means of 2017-2018 and the $3^{\text {rd }}$ one (2019), showing the increase rate in groundnut pod yield fed ${ }^{-1}$ and shelling ratio $\%$.

Generally, pod yield weight registered increase above the previous two seasons for all genotypes except for Line-19A and Sohag-110. On the same line, all genotypes recorded increase in shelling \% except for Line-25A (96.11\%) only, suggesting that increase pod yield production may be conflicted with seed forming or pod filling decreasing shelling \%. These results confirmed that this advanced in production might be based on more salinity-adapted genotypes advantages.

\section{CONCLUSIONS}

From the results, genotypes means showed significantly differences for all pod yield-traits. It can be concluded that selecting genotypes with higher pod yield weight under new soil. Estimating the accurate differences between genotype means require control of error variation either by using adequate experimental design or by effective statistical analysis.

Classical RCBD is adequate experimental design in small number of treatments, when blocking experimental field into homogeneous complete blocks (replications) that reduces experimental error. Meanwhile, RCBD with large number of treatments may clear considerable heterogeneity within-block. 
International Journal of Agriculture and Environmental Research

ISSN: 2455-6939

Volume: 07, Issue: 06 "November-December 2021"

Meanwhile, Alpha lattice design (ALD) is adequate experimental design in large number of treatments that blocking replication into incomplete-blocks can get rid of heterogeneity withinblocks.

However, unaccounted variation may still attend within-incomplete blocks (intra-site variability) (Yang et al. 2004). Restricted maximum likelihood (REML) method provides a more effective and accurate statistical analysis to describe the different levels of variation (Jonson and Thompson 1995). Variance is estimated using residual of REML, which provides unbiased estimates than those obtained by classical methods (Galwey 2006).

The relative efficiency of (ALD) was more efficient compared with RCBD (Masood et al 2018). Meanwhile, REML method was more efficiently for increasing the precision of field trials as compared with other classical least squares analysis (ANOVA) method in RCBD and ALD.

The identification of the best adjusted mean of pod yield for the genotypes was detected under different analysis models which changed their ranking (Singh $\boldsymbol{e t}$ al. 2003). The design of efficient multi-environment test conducted to minimize the variance of differences between genotypes. Compared with classical approaches, REML analysis increased the efficiency of genotype selection for further evaluation.

The highest yielding genotype ranks over the studied checks (Giza 6, Ismailia-2, Suhag 104, Suhag 107 and Suhag 110) produced the best elite ones. Based on three models, Line-25A and Line-110 genotypes scored the highest pod yield, followed by Line-32A, Line-2B, Line-19A, Intro.-335 and Intro.-504, collecting the best promising elite group under new salinity-soil.

\section{REFERENCES}

[1] Abdelkawy R. N. F., A. Z. Turbayev, A. A. Soloviev (2020). Evaluation of Relative Efficiency of Alpha Lattice Design and Cluster Analysis of Twenty Spring Triticale Field Experiments. Indian J. of Agric. Res., 54 (3): 301-307.

[2] Abd El-Saber A., Zeinab E. Ghareeb and M. A. Ahmed (2020). Multivariate Analyses of Yield and Its Components in Some Peanut Genotypes. Asian J. of Advances in Agric. Res. 13(4): 1-15.

[3] Awadalla A. O. and M. T. Abbas (2017). Peanut (Arachis hypogaea L.) yield and its components as affected by $\mathrm{N}$-fertilization and diazotroph inoculation in Toshka desert soil-South Valley-Egypt. Environ Risk Assess Remediat 2017 Volume 1 Issue 3. http://www.alliedacademies.org/environmental-risk-assessment-and-remediation.

[4] Cochran, W. G. and Cox G. M. (1957). Experimental Designs. New York: John Wiley and Sons. 
International Journal of Agriculture and Environmental Research

ISSN: 2455-6939

Volume: 07, Issue: 06 "November-December 2021"

[5] Dean A. and D. Voss (1999). Design and analysis Experiments. Springer Text in Statistics, New York.

[6] Duppala, M. K., N.Beena , K. S. Gowtham, P. D. Pawar and S. R. Patil (2018). Estimating the efficiency of alpha lattice design in preliminary yield trials of mustard. J. of Soils and Crops. 28(1):89-94.

[7] FAO STAT (2019). FAO STAT data of Food and Agriculture Organization of the United Nations

[8] Galwey N. W. (2006). Introduction to Mixed Modeling: Beyond Regression and ANOVA. John wiley \& Sons Ltd., West Sussex, England. 376.

[9] Gabriel Soropa, Olton M. Mbisva, Justice Nyamangara, Ermson Z. Nyakatawa, Newton Nyapwere R. Murray Lark (2021). Spatial variability and mapping of soil fertility status in a high-potential smallholder farming area under sub-humid conditions in Zimbabwe. Applied Sciences 3:396-412 https://doi.org/10.1007/s42452-021-04367-0.

[10] Ghareeb, Zeinab E., H. E. A. Ibrahim and T. S. El-Marsafawy (2015). Evaluating the precision of faba bean field experiments. Bulletin of Fac. of Agric., Cairo Univ. 66: 288296.

[11] Hinkelman K. and O. Kempthorne (2006). Design and Analysis of Experiments. Vols. 1 and 2. Wiley, CT: New York.

[12] John, J. A. and Williams E. R. (1995). Cyclic and Computer Generated Designs $\left(2^{\text {nd }}\right.$ edn.). London: Chapman and Hall.

[13] Johnson D. L. and R. Thompson (1995). Restricted maximum likelihood estimation of variance components for univariate animal models using sparse matrix techniques and average information. J. Dairy. Sci. 78:449-456.

[14] Kaya Başar E. and M. Z. Firat (2016). Comparison of Methods of Estimating Variance Components in Balanced Two-Way Random Nested Designs. Anadolu Univ. J. of Sci. and Tech. B - Theoretical Sci. 4 (1): 1-10.

[15] Kirk, R. E. (1995). Experimental design: procedures for the behavioural science ( $3^{\text {rd }}$ Ed.), Pacific Grove, CA: Brooks/Cole publishing.

[16] Leonardo (2009). Statistical Approaches in Analysis of Variance Journal of sciences, Romania, 15:71-80.

[17] Levene H. (1960). Robust tests for equality of variances. In Ingram Olkin, Harold Hotelling, Etalia, Stanford University press, 278-292.

[18] Lima, J. S. S., Alves, D. I., Coelho, R. I., Sturiao, W. P. and Silva, S. A. (2017). Spatial Variability in the Diagnosis of Nutritional Status in the Papaya. Revista Ciência Agronomica, 47:264-274. 
International Journal of Agriculture and Environmental Research

ISSN: 2455-6939

Volume: 07, Issue: 06 "November-December 2021"

[19] Masood, M. A., Farooq K., Mujahid Y. and Anwar, M. Z. (2008): Improvement in Precision of Agricultural Field Experiments through Design and Analysis. Pak. J. Life Soc. Sci., 6(2): 89-91.

[20] Masood, M.A., Qamar, M. and Raza, I. (2018). Comparative efficiency of alpha lattice design versus randomized complete block design in wheat field trials. Inter. J. of Sci. and Engin. Res.. 9(11): 646-650.

[21] Meyer K (1985). Maximum likelihood estimation of variance components for a multivariate mixed model with equal design matrices. Biometrics 41(1):153-165.

[22] Mick O. N. (2010). ANOVA and REML. A guide to linear mixed models in an experimental design context. Statistical Advisory and Training service Pty Ltd., Sydney, Australia. 172.

[23] Nkhoma N, H. Shimelis, Mark D. Laing, A. Shayanowako and I. Mathew (2020). Assessing the genetic diversity of cowpea [Vigna unguiculata (L.) Walp.] germplasm collections using phenotypic traits and SNP markers. BMC Genetics, 21(110):2-16.

[24] Panhwar F. Oilseed Crops Future in Sindh Pakistan (2005). Digitalvelarg Gmbh, Germany. p:38.

[25] Parsad, R. and V.K. Gupta (2009). Alpha designs, Design resources server. Indian agric. Stat. Res. Inst. (IASRI), New Delhi, India at http://www.iasri.res.in/design/Alpha/home.htm.

[26] Patterson H.D. and Hunter E.A. (1983): The efficiency of incomplete block designs in National List and Recommended cereal variety trials. J. Agric. Sci., 101, 427-433.

[27] Patterson, H. D. and Williams, E. R. (1976). A new class of resolvable incomplete block designs. Biometrika 63:83-92.

[28] Payne, R.W., Murray, D.A., Harding, S.A., Baird, D.B., Soutar, D.M. (2015). Introduction to GenStat for Windows $\left(18^{\text {th }}\right.$ Edition). VSN International, 2 Amberside, Wood Lane, Hemel Hempstead, Hertfordshire HP2 4TP, UK. http://www.genstat.co.uk/

[29] Piepho HP, Möhring J (2011). On estimation of genotypic correlations and their standard errors by multivariate REML using the MIXED procedure of the SAS system. Crop Sci. 51(6):2449-2454.

[30] Rangaswamy, R. (2010). A text book of agricultural statistics. New age international (P) ltd., New Delhi, pp.281-301.

[31] Raza, I. and M. A. Masood (2009). Efficiency of lattice design in relation to randomized complete block design in Agricultural field Experiments. Pakistan J. of Agric. Res., 22:150-153.

[32] Reza Hoshmand, A. (2006): Design of Experiments for Agriculture and the Natural Science, $2^{\text {nd }}$ Edition: Daniel Webster College Nashua, New Hampshire, U.S.A. 
[33] Shalaby M. E., D. A. El-Kadi, A. M. Al-Naggar and M. M. Salem (2018). Spatial, ordinary and meta REML models comparison with traditional statistical analyses for increasing precision of cotton field trials. Academia J. of Agric. Res. 6(5): 150-162.

[34] Singh M., R. S. Malhotra, S. Ceccarelli, A. Sarker, S. Grando And W. Erskine (2003). Spatial Variability Models to Improve Dry land Field Trials. Expl Agric. (2003), volume 39, pp. 151-160. Cambridge University Press. DOI: 10.1017/S0014479702001175 Printed in the United Kingdom

[35] Singh M., W. Tadesse, A. Sarker, F. Maalouf, M. Imtiaz, F. Capettini, and M. Nachit (2013). Capturing the Heterogeneity of the Error Variances of a Group of Genotypes in Crop Cultivar Trials. Crop Sci. 53:811-818 (2013).

[36] Sokal, R. R. and Rohlf, F. J. (1995). Biometry. The Principles and Practice of Statistics in Bio. Res. $3^{\text {rd }}$ Edition. New York: W.H Freeman and Company.

[37] Wu, T. and Dutilleul, P. (1999): Validity and Efficiency of Neighbor Analysis in Comparison with Classical Complete and Incomplete Block Analysis of Field Experiments. Agron. J. 91: 721-731.

[38] Yang, R., Terrance, Z.Y., Stanford, S.B., Manjula, B. (2004). Efficiency of spatial analyses of field pea variety trials. Crop Science. 44(1): 49-55.

[39] Yau S.K. (1997): Efficiency of alpha-lattice designs in international variety yield trials of barley and wheat. The Journal of Agricultural Science, 128, 5-9. 